\title{
Influence of the load of nylon capsules on their passage through the digestive tract and specific gravity
}

\author{
Jiří TřinÁCTÝ ${ }^{\mathrm{a} *}$, Petr HoMOLKA ${ }^{\mathrm{b}}$, Michal RICHTER ${ }^{\mathrm{a}}$, \\ Martin ŠUSTALA a, Aleš VYMĚTAL ${ }^{b}$ \\ ${ }^{a}$ Research Institute of Animal Nutrition, Ltd., 69123 Pohořelice, Czech Republic \\ ${ }^{\mathrm{b}}$ Research Institute of Animal Production, Uhř́něves, 10400 Praha, Czech Republic
}

(Received 10 September 2001; accepted 28 May 2002)

\begin{abstract}
The passage and specific gravity of nylon capsules were evaluated in five trials. In individual trials, different lactating cows were fed the same diet consisting of maize silage, alfalfa hay and concentrate. In each trial the different feeds (or no feed) were used to fill the capsules. The capsules were made of nylon cloth ( $42 \mu \mathrm{m}$ pore size, $10 \mathrm{~mm}$ external diameter). The different weights of the load (L1-L5) were obtained using a combination of 2 and $3 \mathrm{~mm}$ stainless steel balls. The highest recovery of the capsules was obtained with the L3 and L4 loads (91.4 and $92.3 \%$, resp.). After 14 hours of incubation in the rumen, the calculated values of functional specific gravity of the capsules ranged from 0.92 to $2.05 \mathrm{~g} \cdot \mathrm{cm}^{-3}$. It was concluded that L3 (one $2 \mathrm{~mm}$ and one $3 \mathrm{~mm}$ ball) was the suitable weight of the load.
\end{abstract}

passage / nylon capsule / different weight / dairy cow

\section{INTRODUCTION}

The nylon capsule method was published in 1995 [18]. A comparison of this method with the nylon bag and mobile bag methods was published in 1999 [16]; in this experiment the total tract digestibility of protein and dry matter was determined. The results showed that it is possible to use the nylon capsule method for the determination of total tract digestibility of individual feed components in cattle. The main advantage of this method consists in the fact that the experimental animals need not be equipped with canulas. This method was based on the application of nylon capsules of $10 \mathrm{~mm}$ size

* Correspondence and reprints

E-mail: trinacty@vuvz.cz 
filled with a sample of feed and a load. Dosing of capsules into the animal was performed orally. Stainless steel balls (2 and $3 \mathrm{~mm}$ ) were used as the load. The load kept the capsules at the bottom of the rumen and this was the reason why they were not rejected and ruminated. The change of load weight influenced the density of the capsules and this affected the recovery, retention time, first appearance in the faeces, etc. In general, however, the determination of the optimum weight of the load of the capsules is problematic.

The passage of the particles through the digestive tract of ruminants depends on their type, size, time of hydration, etc. When evaluating the passage of the capsules in our study, some data were excerpted from publications describing the passage of plastic particles (with various specific gravity and size) through the digestive tract. Trials with plastic particles have been performed on steers, heifers and dry cows by many authors. The shortest mean retention time and the highest recovery have been obtained with plastic particles with specific gravities ranging from 1.12 to 1.42 or $1.77 \mathrm{~g} \cdot \mathrm{cm}^{-3}$, respectively $[1,2,3,8]$. The evaluation of total mean retention time (TMRT) is important because it has been found that if the TMRT value was high, the particles could stay too long at the bottom of the ventral sac [15] and for that reason recovery is decreased [2]. The maximal amount of ruminated particles in sheep and goats has been recorded at the specific gravity of $0.92 \mathrm{~g} \cdot \mathrm{cm}^{-3}$ [7]. The lowest value of ruminated particles (with specific gravity of $2.15 \mathrm{~g} \cdot \mathrm{cm}^{-3}$ ) was found by [2] in dry cows.

Specific gravity of ruminal digesta determined together with associated gas is sometimes mentioned in the literature as functional specific gravity [6]. Functional specific gravity (FSG) values of roughage feeds were determined by various authors within the range of $0.9-1.4 \mathrm{~g} \cdot \mathrm{cm}^{-3}[4,6$, 18]. Higher values of FSG were recorded with grains and mixtures. After 1 hour of hydration, values of FSG of shelled corn, corn gluten feed and concentrate mixture were determined within the range of $1.17-1.55 \mathrm{~g} \cdot \mathrm{cm}^{-3}$ [12]. Regarding this fact, it can be concluded that the FSG of feeds varies approximately within the range $0.9-1.6 \mathrm{~g} \cdot \mathrm{cm}^{-3}$.

The aim of our work was to find an optimum weight for the load of nylon capsules which give the lowest amount of damaged capsules (by teeth), the highest recovery and the acceptable (not too high) total mean retention time (TMRT). The next goal was to determine the functional specific gravity (FSG) of the capsules with the different load.

\section{MATERIALS AND METHODS}

\subsection{Animals}

Passage evaluation. As experimental animals crossbred dairy cows (Red Holstein $x$ Black Friesian) were used. All the trials were carried out using two dairy cows. In each trial, different animals were used because the trials presented were only a part of another, until now unpublished experiment in which the digestibility of feeds was measured. The results obtained were evaluated in spite of the fact that an increased variability could be expected. The cows were 60-200 days in lactation and their live body weight ranged from 555 to $662 \mathrm{~kg}$. The average milk yields and feed intakes recorded in the individual trials are presented in Table I. In all the trials the diets consisted of maize silage $\left(22.5-38.4 \mathrm{~kg} \cdot \mathrm{day}^{-1}\right.$ on fed basis), alfalfa hay (2.0-4.0 kg.day $\left.{ }^{-1}\right)$ and concentrate $\left(1.5-5.7 \mathrm{~kg} \cdot \mathrm{day}^{-1}\right)$. The concentrate consisted of $32 \%$ maize meal, $19 \%$ rape cakes, $13 \%$ wheat meal, $10 \%$ barley meal, $10 \%$ oat meal, $8 \%$ yeast, $5 \%$ flax meal, $2.5 \%$ mineral mixture and $0.5 \%$ sodium chloride. The diet was designed on the basis of milk performance [14]. The diet components were fed separately. The animals were fed twice a day (at 5.00 a.m. and 3.00 p.m.). 
Table I. Mean daily milk yield and nutrient intake.

\begin{tabular}{|c|c|c|c|c|c|}
\hline Trial & Cow $^{1}$ & $\begin{array}{l}\text { Milk yield } \\
\quad(\text { s.e. }) \\
\left(\mathrm{kg} \cdot \text { day }^{-1}\right)\end{array}$ & $\begin{array}{c}\text { Intake } \\
\text { of dry matter } \\
\left(\mathrm{kg} \cdot \mathrm{day}^{-1}\right)\end{array}$ & $\begin{array}{l}\text { Intake } \\
\text { of crude protein } \\
\left(\mathrm{kg} \cdot \mathrm{day}^{-1}\right)\end{array}$ & 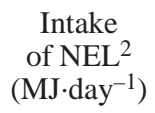 \\
\hline \multirow[t]{2}{*}{$\mathrm{T} 1$} & 1 & $12.1(0.10)$ & 16.7 & 1.87 & 110 \\
\hline & 2 & $10.3(0.11)$ & 14.6 & 1.66 & 96 \\
\hline \multirow[t]{2}{*}{$\mathrm{T} 2$} & 3 & $10.9(0.12)$ & 16.9 & 1.89 & 111 \\
\hline & 4 & $8.6(0.11)$ & 14.5 & 1.64 & 95 \\
\hline \multirow[t]{2}{*}{ T3 } & 5 & $8.6(0.14)$ & 14.8 & 1.97 & 93 \\
\hline & 6 & $9.5(0.25)$ & 16.6 & 2.12 & 105 \\
\hline \multirow[t]{2}{*}{ T4 } & 7 & $12.7(0.19)$ & 12.6 & 1.87 & 78 \\
\hline & 8 & $12.8(0.19)$ & 14.7 & 2.11 & 92 \\
\hline \multirow[t]{2}{*}{ T5 } & 9 & $19.3(0.30)$ & 20.5 & 2.63 & 131 \\
\hline & 10 & $20.3(0.44)$ & 18.9 & 2.53 & 120 \\
\hline
\end{tabular}

${ }^{1}$ In individual trials, different cows were used.

${ }^{2} \mathrm{NEL}$ - nettoenergie of lactation [14].

The functional specific gravity was determined by incubation of the capsules in the rumen of three cannulated mature oxes. The animals were equipped with $10 \mathrm{~cm}$ rumen cannula (Bar Diamond, USA). The diet of the oxes was as follows: $2 \mathrm{~kg}$ of mixture, $4 \mathrm{~kg}$ of alfalfa hay and $6 \mathrm{~kg}$ of corn silage.

\subsection{Nylon capsule content and passage evaluation}

The nylon capsule passage evaluation was made in five trials. Each trial included a preparatory period (14 days) and two experimental periods $(2 \times 4$ days $)$ with a three-day pause. The capsules were made of nylon cloth (Uhelon, Hedva Moravská Třebová) with $42 \mu \mathrm{m}$ apertures according to [16]. The capsules had a lenticular shape with outside and inside diameters of 10 and $8 \mathrm{~mm}$, respectively. The capsules were applied orally in the form of a paper bolus. Five various weights of loads (L1-L5) were used. Different weights of loads were obtained by means of a combination of
$2(0.0338 \mathrm{~g})$ and $3 \mathrm{~mm}(0.1156 \mathrm{~g})$ stainlesssteel balls. The combination of balls and the total weights of the load are presented in Table II. In all five trials (T1-T5), the same combinations of stainless-steel balls were used; feed samples in the capsules, were however, different. In the T1-T4 trials various kinds and amounts of feed were used (Tab. II), in the T5 trial the capsules did not contain any feed. The weight of the empty capsules (without feed and load) was $0.0475 \mathrm{~g}$. All feeds were milled through a $1 \mathrm{~mm}$ screen.

The weighing of the feed for the capsules was made in batches. Each batch involved 100 capsules. The capsules were produced manually in our laboratory. To calculate the quantity of feed in one capsule, the total amount of feed used for one batch was divided by the number of capsules in the corresponding batch. For one determination in one cow, 500 capsules were needed (5 loads, L1 to L5; -100 capsules per load). This means that the number of capsules used in one trial (two cows, two periods) was 
Table II. Number and weight of balls, weight of feed sample in capsules with the L1-L5 load in individual trials T1-T5.

\begin{tabular}{lccccc}
\hline & \multicolumn{5}{c}{ Content of capsules according to weight of load } \\
\cline { 2 - 6 } & L1 & L2 & L3 & L4 & L5 \\
\hline Balls: & & & & & \\
Number (pcs) & $2 \times 2 \mathrm{~mm}$ & $1 \times 3 \mathrm{~mm}$ & $1 \times 3 \mathrm{~mm}$ & $1 \times 3 \mathrm{~mm}$ & $1 \times 3 \mathrm{~mm}$ \\
& & & $1 \times 2 \mathrm{~mm}$ & $2 \times 2 \mathrm{~mm}$ & $3 \times 2 \mathrm{~mm}$ \\
Weight (g) & 0.0675 & 0.1132 & 0.1470 & 0.1807 & 0.2145 \\
Feed sample (g): & & & & & \\
T1 alfalfa hay & $0.0157(12.0)^{1}$ & $0.0151(8.5)$ & $0.0151(7.1)$ & $0.0146(5.9)$ & $0.0149(5.3)$ \\
T2 maize silage & $0.0145(11.2)$ & $0.0142(8.0)$ & $0.0144(6.8)$ & $0.0148(6.0)$ & $0.0152(5.4)$ \\
T3 rape expeller-1 & $0.0154(11.8)$ & $0.0150(8.4)$ & $0.0153(7.2)$ & $0.0152(6.2)$ & $0.0154(5.5)$ \\
T4 rape expeller-h & $0.0355(23.6)$ & $0.0353(17.8)$ & $0.0353(15.2)$ & $0.0353(13.3)$ & $0.0357(11.9)$ \\
T5 without feed & $0(0.0)$ & $0(0.0)$ & $0(0.0)$ & $0(0.0)$ & $0(0.0)$ \\
\hline
\end{tabular}

${ }^{1}$ In the brackets is the percentage of weight of feed sample in the total weight of the capsules.

2 Weight of empty capsule (without feed and load) was $0.0475 \mathrm{~g}$.

2000. All capsules were marked with an ineffaceable colour, and each cow and each capsule with different loads had colours of their own. The capsules damaged (marked) by teeth were found in the faeces and were counted as chewed capsules. The total collection of the faeces was done at 6-hour intervals for the first 18 hours, then at 3 -hour intervals and in the last 48 hours at 6-hour intervals again. Once every 24 hours, the capsules were recovered from the faeces by washing on a $4 \mathrm{~mm}$ screen.

Capsule mean retention time in the total digestive tract (TMRT) was calculated according to [9]: $\mathrm{TMRT}=\sum(\mathrm{Ni} \times \mathrm{ti} \times \Delta \mathrm{ti}) /$ $\sum(\mathrm{Ni} \times \Delta \mathrm{ti})$, where $\mathrm{Ni}$ is the number of capsules collected in the faeces during the interval $\Delta \mathrm{ti}$ and ti is the time elapsed from dosing to the midpoint of the collection interval $\Delta$ ti.

The first appearance time of the capsules in the faeces (FAC) was determined by the time elapsing between dosing and the midpoint of the interval when the capsules appeared in the faeces for the first time. This determination was done according to [9].

\subsection{Determination of specific gravity}

The specific gravity of the capsules in the rumen could not be measured directly because of the content of gas. For this reason the specific gravity of the capsules with feed (or no feed, respectively) and of the stainless steel balls was determined individually. FSG was calculated after the determination of gas content. Before the estimation of FSG, it was necessary to calculate the time of incubation in the rumen.

\subsubsection{Estimation of the time of incubation in the rumen}

It was assumed that the capsules after application immediately sank to the bottom of the ventral sac. After hydration and changes in the gas content (pressing up the air and fermentation starting), the capsules left the rumen. We tried to define the time interval from the capsules application to the maximum flow of the capsules from the rumen. This time interval was used for the incubation of the capsules. Estimation of this time was done by means of a two 
compartment age-dependent and age-independent (G2G1) model. This model was chosen because it enabled to calculate two retention times in two individual compartments [11]. For fitting of the results obtained the equation published by [11] was used, this one was similar to the equation presented by [20]:

$$
\begin{aligned}
& \mathrm{Y}=\mathrm{D} *\left(1-\left(\delta^{2 *} \mathrm{e}^{-\mathrm{k}^{*}(\mathrm{~h}-\tau)}+\mathrm{e}^{-\lambda *(\mathrm{~h}-\tau) *\left(1-\delta^{2}\right.}\right.\right. \\
& +(1-\delta) * \lambda *(h-\tau)))),
\end{aligned}
$$

where $\delta=\lambda /(\lambda-\mathrm{k}) ; \lambda=$ rate parameter for gamma-distributed residence times; $\mathrm{k}=$ rate parameter for exponentially distributed residence times; $\mathrm{h}=$ time after dose of the capsules; $\tau=$ time delay between dose and first detection of the capsules in the faeces. We tried to compare the curves of the individual data obtained in individual cows and loads with model ones but it was found that the results were inconsistent. A similar observation for individual data curves was mentioned by [20]. For this reason the individual mean was calculated for each time interval (from all data in this time interval) and the curve was fitted through this mean data.

For the calculation of the first compartment retention time (CMRT1), the following equation was used: CMRT1 $=\mathrm{n} / \lambda$, where $n$ represents the order of gamma function (in our case $n=2$ ) and CMRT2 $=1 / \mathrm{k}$, the second compartment retention time. According to [11], the calculated CMRT1 is identical to the time of maximum outflow of particles (capsules) from the rumen.

\subsubsection{Specific gravity of capsules with feed (or no feed, respectively)}

The T1-T5 capsules (without stainless steel balls) were incubated for 14 hours in the rumen of three cannulated oxes. Five capsules of each type (T1-T5) were inserted through a cannula after feeding. The capsules were covered in a net (mesh $1 \mathrm{~mm}$ ), loaded with $300 \mathrm{~g}$ weight and manually put into the bottom of the rumen. The amounts of feed in the capsules are presented in
Table II. After incubation (the time calculated for incubation was $14 \mathrm{~h}$ ), the capsules were placed in prepared solutions of $\mathrm{NaCl}$ with various specific densities (the scale was $0.05 \mathrm{~g} \cdot \mathrm{cm}^{-3}$, range $1.0-1.20 \cdot \mathrm{cm}^{-3}$ ) and were squeezed with fingers under the solution surface to remove gas.

\subsubsection{Weight of capsules with feed (or no feed, respectively) after incubation}

After the determination of specific gravity, the capsules were again lightly washed in cold water and centrifugated for 1 minute (10000 rotations per minute) on filter paper. During centrifugation, the capsules were covered with aluminium foil to prevent their drying. After centrifugation the capsules were weighed immediately.

\subsubsection{Stainless steel balls}

The specific gravity of 2 and $3 \mathrm{~mm}$ balls was determined with a $50 \mathrm{~mL}$ pycnometer. For this purpose 200 balls or 800 balls of $3 \mathrm{~mm}$ and $2 \mathrm{~mm}$ size, respectively, were used.

\subsubsection{Determination of the gas content in the capsules}

The amount of gas was measured only with the L3 load in all variants T1-T5. It was supposed that the differences in gas content among L3 and the other variants of the loads were negligible. Twenty capsules were covered in a net (mesh $1 \mathrm{~mm})$, were loaded with $300 \mathrm{~g}$ weight and were incubated for 14 hours (time determined according to the procedure developed by [20], described above) in the rumen of each of 3 cannulated oxes. After incubation, the net with the capsules was placed into a polyethylene beaker under the level of rumen liquid. The beaker with the capsules and rumen liquid was thereafter removed and inserted into a thermobox $\left(39^{\circ} \mathrm{C}\right)$. In the laboratory the net was opened under the 
level of the rumen liquid and the capsules were transferred with a spoon into a larger beaker (3 litres) filled with a buffer solution $\left(39^{\circ} \mathrm{C}\right)$ to prevent dissolving of the gas from the capsules. The buffer consisted of (in 1 liter) distilled water, $5.7 \mathrm{~g} \mathrm{Na} \mathrm{HPO}_{4}$ (anhydrous), $6.2 \mathrm{~g} \mathrm{KH}_{2} \mathrm{PO}_{4}$ (anhydrous), $0.6 \mathrm{~g} \mathrm{MgSO}_{4} \cdot 7 \mathrm{H}_{2} \mathrm{O}$. This solution was then saturated with carbon dioxide [5]. A turned funnel connected with a $5 \mathrm{~mL}$ pipette, filled with the same solution, was immersed into this solution. The individual capsules were pressed with fingers under the liquid surface to expel bubbles of gas. These bubbles were trapped with the funnel and the amount of gas from the 20 capsules was measured using a pipette. Measuring was carried out in a box at $39^{\circ} \mathrm{C}$.

\subsubsection{Functional specific gravity}

The functional specific gravity (FSG) of the capsules after $14 \mathrm{~h}$ of incubation was calculated according to the formula:

$F S G=\left(a+b^{*} c+d^{*} e\right) /\left(f+b^{*} g+d^{*} h+i\right)$, where $\mathrm{a}=$ weight of the capsules with feed (or no feed, respectively); $b=$ number of $3 \mathrm{~mm}$ balls; $\mathrm{c}=$ weight of $3 \mathrm{~mm}$ ball; $\mathrm{d}=$ number of $2 \mathrm{~mm}$ balls; $\mathrm{e}=$ weight of $2 \mathrm{~mm}$ ball; $\mathrm{f}=$ volume of capsules with feed (or no feed, respectively); $\mathrm{g}=$ volume of $3 \mathrm{~mm}$ ball; $\mathrm{h}=$ volume of $2 \mathrm{~mm}$ balls; $\mathrm{i}=$ gas content in the capsule. Parameter $\mathrm{f}$ was calculated by dividing the weight of the capsules by their specific gravity.

\subsection{Statistical analysis}

The recovery of the capsules and the number of chewed capsules were evaluated using multifactorial analysis of variance (after arcsin transformation) with a splitplot design [13] (Unistat, ver. 4.51 and manually with the help of Microsoft Excel 97) according to the following model:

$$
Y_{i j k}=\mu+\alpha_{i}+\beta_{j}+\varepsilon_{i j}+\gamma_{k}+(\alpha \gamma)_{i k}+\phi_{i j k},
$$

where $Y_{i j k}=$ a dependent variable for trial $\mathrm{i}$, repetitions $\mathrm{j}$ and load $\mathrm{k} ; \mu=$ overall mean; $\alpha_{i}=$ effect of the trial ( $i=1$ to 5 ); $\beta_{j}=$ the effect of the cows and periods (repetitions) $(\mathrm{j}=1$ to 4$) ; \varepsilon_{\mathrm{ij}}=$ random residual $\alpha_{\mathrm{i}}$ and $\beta_{\mathrm{j}}$; $\gamma_{\mathrm{k}}=$ effect of load ( $\mathrm{k}=1$ to 5$) ;(\alpha \gamma)_{\mathrm{ik}}=$ interaction of $\alpha_{i}$ and $\gamma_{k} ; \phi_{i j k}=$ random residual of $\gamma_{\mathrm{k}}$ and $(\alpha \gamma)_{\mathrm{ik}}$. Values of TMRT and FAC were evaluated in a similar way but without an arcsin transformation of the values.

The recovery of the capsules at intervals of $24,48,72$ and $96 \mathrm{~h}$ after the dose to the appearance in the faeces were evaluated by analysis of variance (after using an arcsin transformation) of the values according to the following model:

$$
\begin{aligned}
Y_{i j k l}= & \mu+\alpha_{i}+\beta_{j}+\varepsilon_{i j}+\gamma_{k}+\delta_{1}+(\alpha \gamma)_{i k} \\
& +(\alpha \delta)_{i l}+\left(\gamma \delta_{k 1}\right)+\phi_{i j k l},
\end{aligned}
$$

where $\mathrm{Y}_{\mathrm{ijkl}}=$ dependent variable for $\mathrm{i}$; $\mathrm{j}, \mathrm{k}$ (see above) and time intervals 1 , symbols $\mu, \alpha_{\mathrm{i}}, \beta_{\mathrm{j}}, \varepsilon_{\mathrm{ij}}, \gamma_{\mathrm{k}}$, and $(\alpha \gamma)_{\mathrm{ik}}$ are described above, $\delta_{1}=$ effect of time intervals (time from the dose to the appearance in the faeces) $24,48,72$ and $96,(1=1$ to 4$),(\alpha \delta)_{\mathrm{i} 1}=$ interaction of $\alpha_{i}$ and $\delta_{1},\left(\gamma \delta_{k 1}\right)=$ interaction of $\gamma_{\mathrm{k}}$ and $\delta_{1} ; \phi_{\mathrm{ijkl}}=$ random residual of $\gamma_{\mathrm{k}}$, $\delta_{1},(\alpha \gamma)_{\mathrm{ik}},(\alpha \delta)_{\mathrm{il}}$, and $\left(\gamma \delta_{\mathrm{kl}}\right)$. When the effect was significant, the means were compared by the Scheffe test.

The FSG of the capsules was evaluated using two-way analysis of variance (Unistat, ver. 4.51). If the effect was significant, the means were compared with the Scheffe test.

\section{RESULTS AND DISCUSSION}

\subsection{Passage evaluation}

In trials $\mathrm{T} 1-\mathrm{T} 4$, the milk yield (ranging from 8.6 to $12.0 \mathrm{~kg} \cdot \mathrm{day}^{-1}$ ) and intake of the nutrients varied within a narrow range; in the T5 trial, a higher milk yield (19.3 and $20.3 \mathrm{~kg} \cdot$ day $^{-1}$ was associated with a much higher level of intake (Tab. I). Milk yield was in a good fit with the calculated [14] consumption of nutrients. 
As mentioned in Table II, the total weight of the load in the capsules ranged from $0.0675 \mathrm{~g}$ (L1) to $0.2145 \mathrm{~g}$ (L5) and the feed amount in the capsules ranged from $0.0142 \mathrm{~g}$ to $0.0357 \mathrm{~g}$ and/or zero, respectively. Since the load of the capsule increased progressively from treatments L1 to L5 and the sample weight was much smaller than the loads and remained either quite constant (trial T1 to T4) or zero (trial T5), the contribution of the feed sample weight to the capsule weight was mostly small (not in L1 and L2) and decreased (or was zero) from the L1 to L5 treatments. The lowest share of the feed in the total weight of the capsules was 0.0 or $5.3 \%$, respectively while the highest one was $23.6 \%$.

Capsule recovery, TMRT, first appearance (FAC) and percentage of chewed capsules in the individual trials are presented in Table III. Variations in the T1-T5 trials resulted partly from controllable factors (type and amount of feed) and partly from uncontrollable factors (animals). Since our trial was designed in this way, it was decided to use the split-plot type of variance analysis. According to [13], the sub-plot treatments (in our case the loads) were not randomised over the whole large block but only over the main plots (in our case the trials and cows + periods). A consequence of this design was that the experimental error of sub-treatments (loads) was smaller than that of main treatments (trials and cows + periods).

The mean recovery of the capsules with L1-L5 in the individual trials was significantly $(P<0.05)$ higher in T5 $(91.2 \%)$. This could be caused by a higher intake of dry matter observed in this trial similarly as in our earlier experiment [17]; a higher intake of dry matter in cows accelerated the flow of particles through the digestive tract. Some significant differences $(P<0.05)$ were found for TMRT values (T1 and T2 vs. T3) and it was supposed that in this case the main sources of variability was the individuality of the experimental animals. FAC values did not show high differences $(P>0.05)$ among individual trials. The lowest value of the chewed capsules was at T4 $(2.6 \%)$ and, as compared with T1 $(8.8 \%)$ and $\mathrm{T} 2$ $(12.2 \%)$, the differences were significant $(P<0.05)$. This can be explained by the fact that the T4 capsules contained the lowest amounts of gas $\left(0.043 \mathrm{~mL} \cdot\right.$ capsule $\left.^{-1}\right)$. In our opinion the doubled weight of rape expellers fulfilled the space of the capsules and reduced the amount of gas. For this reason, the capsules were not upheld in the rumen content and could easily escape the chewing.

The evaluation of recovery, TMRT, FAC and chewed capsules according to the variation of the loads in the capsules is presented in Table IV. The cumulative excretion curves of the capsules with all collection

Table III. Fecal recovery $96 \mathrm{~h}$ after dosing, mean retention time in the total tract (TMRT), first appearance of the capsules in the faeces (FAC) and chewed capsules in the individual trials with the L1 to L5 loads.

\begin{tabular}{lcccccc}
\hline Item & Unit & \multicolumn{5}{c}{ Trial } \\
\cline { 3 - 7 } & & T1 & T2 & T3 & T4 & T5 \\
\cline { 4 - 8 } & & & & & & \\
Recovery of the capsules (L1-L5) & $(\%)$ & $74.1^{\mathrm{a}}$ & $79.8^{\mathrm{a}}$ & $81.8^{\mathrm{a}}$ & $78.4^{\mathrm{a}}$ & $91.2^{\mathrm{b}}$ \\
TMRT of the capsules (L1-L5) & $(\mathrm{h})$ & $49.6^{\mathrm{b}}$ & $51.1^{\mathrm{b}}$ & $38.0^{\mathrm{a}}$ & $46.4^{\mathrm{ab}}$ & $42.3^{\mathrm{ab}}$ \\
Values of FAC (L1-L5) & $(\mathrm{h})$ & 25.8 & 23.4 & 19.9 & 21.5 & 20.0 \\
Values of the chewed capsules (L1-L5) & $(\%)$ & $8.8^{\mathrm{b}}$ & $12.2^{\mathrm{b}}$ & $6.6^{\mathrm{ab}}$ & $2.6^{\mathrm{a}}$ & $8.4^{\mathrm{ab}}$ \\
\hline
\end{tabular}

Values with different letters in the same rows differ significantly $(P<0.05)$. 
Table IV. Recovery, total mean retention time (TMRT), chewed capsules and the first appearance of capsules in the faeces (FAC) according to individual weights of the loads of the capsules.

\begin{tabular}{|c|c|c|c|c|c|c|}
\hline \multirow[t]{2}{*}{ IItem } & \multirow[t]{2}{*}{ Unit } & \multicolumn{5}{|c|}{ Capsules with the load } \\
\hline & & L1 & L2 & L3 & L4 & L5 \\
\hline Recovery at $24 \mathrm{~h}$ (T1-T5) & $(\%)$ & $4.1^{\mathrm{bc}}$ & $8.2^{\mathrm{c}}$ & $6.0^{\mathrm{bc}}$ & $2.3^{\mathrm{ab}}$ & $0.9^{\mathrm{a}}$ \\
\hline Recovery at $48 \mathrm{~h}$ (T1-T5) & $(\%)$ & $37.2^{\mathrm{a}}$ & $65.9^{\mathrm{cd}}$ & $72.7^{\mathrm{d}}$ & $63.8^{\mathrm{c}}$ & $48.6^{\mathrm{b}}$ \\
\hline Recovery at $72 \mathrm{~h}$ (T1-T5) & $(\%)$ & $49.2^{\mathrm{a}}$ & $77.7^{\mathrm{b}}$ & $89.1^{\mathrm{c}}$ & $86.9^{c}$ & $80.1^{\text {bc }}$ \\
\hline Recovery at $96 \mathrm{~h}$ (T1-T5) & $(\%)$ & $52.5^{\mathrm{a}}$ & $80.5^{\mathrm{b}}$ & $91.4^{\mathrm{c}}$ & $92.3^{\mathrm{c}}$ & $88.7^{\mathrm{c}}$ \\
\hline Values of TMRT (T1-T5) & (h) & $45.2^{\mathrm{b}}$ & $40.1^{\mathrm{a}}$ & $41.8^{\mathrm{a}}$ & $47.3^{\mathrm{b}}$ & $53.0^{\mathrm{c}}$ \\
\hline Values of FAC (T1-T5) & (h) & $20.4^{\mathrm{ab}}$ & $19.3^{\mathrm{a}}$ & $21.4^{\mathrm{ab}}$ & $24.0^{\mathrm{bc}}$ & $25.5^{\mathrm{c}}$ \\
\hline Values of chewed capsules (T1-T5) & $(\%)$ & $19.1^{\mathrm{d}}$ & $9.2^{\mathrm{c}}$ & $4.8^{\mathrm{b}}$ & $3.1^{\mathrm{ab}}$ & $2.3^{\mathrm{a}}$ \\
\hline
\end{tabular}

Values with different letters in individual rows differ significantly $(P<0.05)$.

Table V. Weight of capsules, their specific gravity and gas content after $14 \mathrm{~h}$ of incubation.

\begin{tabular}{lcccc}
\hline Trial & Feed & $\begin{array}{c}{ }^{1} \text { Mean weight of } \\
\text { capsule, } n=15 \\
\text { (in brackets }- \text { s.e. }) \\
(\mathrm{g})\end{array}$ & $\begin{array}{c}{ }^{1} \text { Mean specific gravity } \\
\text { of capsule, } n=15 \\
\text { (in brackets }- \text { s.e. }) \\
\left(\mathrm{g} \cdot \mathrm{cm}^{-3}\right)\end{array}$ & $\begin{array}{c}{ }^{2} \text { Mean gas content in one } \\
\text { capsule, } n=3 \\
\text { (in brackets }- \text { range) } \\
(\mathrm{mL})\end{array}$ \\
\hline $\mathrm{T} 1$ & alfalfa hay & $0.229(0.0007)$ & $1.08(0,000)$ & $0.055(0.045-0.063)$ \\
$\mathrm{T} 2$ & maize silage & $0.224(0.0009)$ & $1.12(0.005)$ & $0.052(0.048-0.055)$ \\
T3 & rape expeller-1 & $0.220(0.0010)$ & $1.10(0.007)$ & $0.047(0.045-0.048)$ \\
T4 & rape expeller-h & $0.233(0.0009)$ & $1.13(0,000)$ & $0.043(0.035-0.053)$ \\
T5 & without feed & $0.203(0.0004)$ & $1.08(0.003)$ & $0.074(0.070-0.078)$ \\
\hline
\end{tabular}

${ }^{1}$ Determination was done with capsules filled by feed (or no feed, resp.) without balls.

${ }^{2}$ Determination was done with capsules filled by feed (or no feed, resp.) and with one, 2 and $3 \mathrm{~mm}$ ball.

intervals are shown in Figure 1. As mentioned in Table IV, it can be seen that the lowest recovery was found in all time intervals for the L1 and L2 loads. The capsules with the L5 load had a recovery of $88.7 \%$, four days (96 h) after insertion; this was a satisfactory result but after 48 and $72 \mathrm{~h}$ time intervals, relatively lower values (as compared with L3 and L4) were found (48.6 and $80.1 \%$, resp.). The highest recovery values were obtained for capsules with L3 (91.4\%) and L4 (92.3\%) loads. After 96 hours, the differences from L1 $(52.5 \%)$ and L2 $(80.5 \%)$ were significant $(P<0.05)$.
The lowest TMRT of T1-T5 was found with the L2 and L3 loads (40.1 and $41.8 \mathrm{~h}$, respectively), the highest $(P<0.05)$ value at L5 was $53.0 \mathrm{~h}$. The TMRT of L5 seems to be too high, probably due to the fact that the capsules could lie on the bottom of the rumen [15]. This observation was in agreement with lower recovery values of L 5 after 48 and 72 h time intervals. For this reason, it was supposed that the passage of these capsules through the digestive tract was slower.

The lowest mean values of FAC of T1-T5 were recorded with the L1-L3 loads. The 
Figure 1. Cumulative recovery of the capsules in the faeces with the L1-L5 loads.

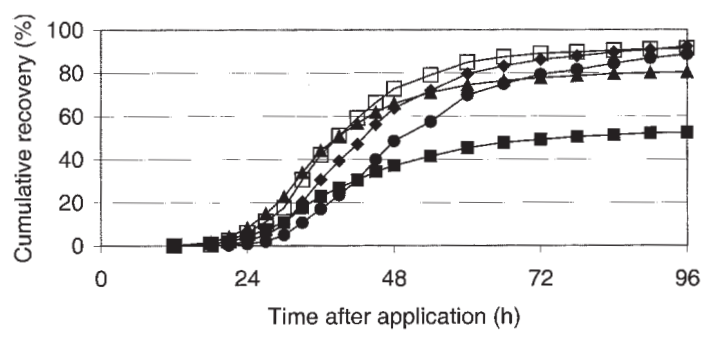

heaviest capsules (L5) had a value of $25.5 \mathrm{~h}$. The differences were not high although some of them were significant $(P<0.05)$. For the time being, we cannot evaluate the value of FAC from the viewpoint of the nylon capsule method because of a lack of information. Higher mean values of chewed capsules of T1-T5 were found at L1, the lightest load $(19.1 \%)$, the lowest number was found at L5 $(2.3 \%)$, the differences between individual loads were mostly significant $(P<0.05)$. The nylon capsule method could therefore be more efficient with the lowest number of chewed capsules (L3, L4 and L5).

\subsection{Functional specific gravity evaluation}

The partial results needed for FSG calculation (i.e. weight of the capsules, their specific gravity and gas content after $14 \mathrm{~h}$ of incubation) are presented in Table V. Gas content was the lowest $(0.043 \mathrm{~mL})$ in the
T4 variant, because of a doubled weight of feed $(0.0353-0.0357 \mathrm{~g}$; Tab. II). It is supposed that in this case the feed fulfilled the space of the capsule and the gas was expelled. Empty capsules (without feed) had $0.074 \mathrm{~mL}$ of gas and we suppose that this gas partly originated from the air which was present in the capsules before immersion into the rumen. FSG values of complete capsules are presented in Table VI. In capsules filled with feed, the mean FSG values of the individual trials were found within a narrow range $\left(1.51-1.64 \mathrm{~g} \cdot \mathrm{cm}^{-3}\right)$. If the capsules were without feed, the mean value of the T5 trial $\left(1.38 \mathrm{~g} \cdot \mathrm{cm}^{-3}\right)$ was out of this range $(P<0.05)$. A markedly higher range of FSG was found with the capsules containing the various L1-L5 loads $\left(1.09-1.93 \mathrm{~g} \cdot \mathrm{cm}^{-3}\right)$; all differences among individual means were significant $(P<0.05)$.

As mentioned above, the capsules with the L1 and L2 loads showed a higher percentage of damage by teeth. This means that a suitable load was L3 (and higher) with

Table VI. Calculated FSG values of capsules with the L1-L5 load $\left(\mathrm{g} \cdot \mathrm{cm}^{-3}\right)$.

\begin{tabular}{lccccccc}
\hline Trial & Feed sample & L1 & L2 & L3 & L4 & L5 & Mean \\
T1 & alfalfa hay & 1.07 & 1.35 & 1.54 & 1.72 & 1.89 & $1.51^{\mathrm{B}}$ \\
T2 & maize silage & 1.12 & 1.40 & 1.60 & 1.78 & 1.96 & $1.57^{\mathrm{C}}$ \\
T3 & rape expeller-1 & 1.16 & 1.46 & 1.67 & 1.86 & 2.05 & $1.64^{\mathrm{D}}$ \\
T4 & rape expeller-h & 1.20 & 1.47 & 1.66 & 1.83 & 2.00 & $1.63^{\mathrm{D}}$ \\
T5 & without feed & 0.92 & 1.21 & 1.41 & 1.59 & 1.77 & $1.38^{\mathrm{A}}$ \\
Mean & - & $1.09^{\mathrm{a}}$ & $1.38^{\mathrm{b}}$ & $1.58^{\mathrm{c}}$ & $1.76^{\mathrm{d}}$ & $1.93^{\mathrm{e}}$ & - \\
\hline
\end{tabular}

Values with different letters in the row $\left({ }^{\mathrm{a}, \mathrm{b}, \mathrm{c}, \mathrm{d}, \mathrm{e}}\right)$ or column (A,B,C,D) differ significantly $(P<0.05)$. 
values of FSG $1.58 \mathrm{~g} \cdot \mathrm{cm}^{-3}$ (and more). Depending on size, time of hydration etc., literary FSG values of forages range mostly from 0.9 to $1.3 \mathrm{~g} \cdot \mathrm{cm}^{3-1}[6,10,12]$. A higher value of FSG has been found for grain, for example [19] mentioned $1.37-1.55 \mathrm{~g} \cdot \mathrm{cm}^{-3}$. Plastic particles with the specific gravity 1.77-2.15, or 2.30, respectively, have been applied by [2 and 3 ] into dry cows or heifers, respectively, resulting in a low recovery and a high retention time. There is a lack of data on the passage of high specific gravity (or FSG, resp.) particles through the digestive tract of lactating cows. In our opinion, a high FSG of the capsules enabled their passage through the digestive tract in spite of the fact that their size was $10 \mathrm{~mm}$. This could also be the reason that only a small part of the capsules was chewed (at L3 $4.8 \%$ ). According to the results of our earlier study [17], this could be achieved only in lactating cows with a high intake of DM and a high rate of digesta flow.

\section{CONCLUSIONS}

The highest recovery values were obtained with capsules containing the L3 and L4 loads and the lowest TMRT was observed with the L2 and L3 loads. The lowest number of chewed capsules was found with L3, L4 and L5. It can be concluded that a suitable weight of load was L3 (one $2 \mathrm{~mm}$ and one $3 \mathrm{~mm}$ ball). Satisfactory results were also obtained with L4. Mean values of capsules' functional specific gravity with L3 and L4 were 1.58 and $1.76 \mathrm{~g} \cdot \mathrm{cm}^{-3}$, respectively.

\section{ACKNOWLEDGEMENTS}

The authors would like to express their thanks to V. Hlaváč ek, B. Hutárková for their assistance in the research and to Professor L. Zeman from Mendel University of Agriculture and Forestry Brno for his constructive comments. This research was supported by GAČR agency, Project No 523/99/1539.

\section{REFERENCES}

[1] Campling R.C., Freer M., The effect of specific gravity and size on the mean time of retention of inert particles in the alimentary tract of the cow, Br. J. Nutr. 16 (1962) 507-518

[2] Des Bordes C.K., Welch J.G., Influence of specific gravity on rumination and passage of indigestible particles, J. Anim. Sci. 59 (1984) 470-475.

[3] Ehle F.R., Stern M.D., Influence of particle size and density on particulate passage through alimentary tract of Holstein heifers, J. Dairy Sci. 69 (1986) 564-568.

[4] Evans E.W., Pearce G.R., Burnett J., Pillinger S.L., Changes in some physical characteristics of the digesta in the reticulo-rumen of cows fed once daily, Br. J. Nutr. 29 (1973) 357-376.

[5] Goering H.K., Van Soest P.J., Forage fiber analyses (apparatus, reagents, procedures, and some applications), Agric. Handbook No. 379, ARSUSDA, Washington, DC, 1970, pp. 387-598.

[6] Hooper A.P., Welch J.G., Effects of particle size and forage composition on functional specific gravity, J. Dairy Sci. 68 (1985) 1181-1188.

[7] Katoh K., Sato F., Yamazaki A., Sasaki Y. Tsuda T., Passage of indigestible particles of various specific gravities in sheep and goats, Br. J. Nutr. 60 (1988) 683-687.

[8] King K.W., Moore W.E.C., Density and size as factors affecting passage rate of ingesta in the bovine and human digestive tracts, J. Dairy Sci. 40 (1957) 528-536

[9] Mambrini M., Peyraud J.L., Retention time of feed particles and liquids in the stomachs and intestines of dairy cows. Direct measurement and calculations based on faecal collection, Reprod. Nutr. Dev. 37 (1997) 427-442.

[10] Nocek J.E., Kohn R.A., Initial particle form and size on change in functional specific gravity of alfalfa and Timothy hay, J. Dairy Sci. 70 (1987) 1850-1863.

[11] Pond K.R., Ellis W.C., Matis J.H., Ferreiro H.M., Sutton J.D., Compartment models for estimating attributes of digesta flow in cattle, Br. J. Nutr. 60 (1988) 571-595.

[12] Siciliano-Jones J., Murphy M.R., Specific gravity of various feedstuffs as affected by particle size and in vitro fermentation, J. Dairy Sci. 74 (1991) 896-901.

[13] Snedecor G.W., Cochran W.G., Statistical methods, The Iowa State University Press, Ames, Iowa, USA, 6th ed., 1973, 593 p.

[14] Sommer A., (editor) Nutrient requirements and tables of nutrients for ruminants, CAZ, Pohorelice (1994) $197 \mathrm{p}$.

[15] Tř ináctý J., Schmeiserová L., Suchý P., Passage and retaining of plastic particles in digestive tract of dry cows, Czech J. Anim. Sci. 44 (1999) 263-268. 
[16] Třináctý J., Šimek M., Homolka P., Nylon capsule method and alfalfa hay crude protein digestibility evaluation, Anim. Feed Sci. Technol. 79 (1999) 269-278.

[17] Třrináctý J., Šimek M., Zeman L., Harazim., Passage of large plastic particles through the digestive tract of lactating and dry cows, J. Anim. and Feed Sci. 8 (1999) 263-272.

[18] Třináctý J., Svozil B., Šimek M., Digestibility evaluation of neutral sugars from hemicellulose of alfalfa hay by nylon capsule method, in: IV. International Symposium on the Nutrition of Herbivores, Clermont-Ferrand, Ann. Zootech. Suppl. 44 (1995) 189.

[19] Wattiaux M.A., Mertens D.R., Satter L.D. Effect of source and amount of fiber on kinetics of digestion and specific gravity of forage particles in the rumen, J. Dairy Sci. 74 (1991) 3872-3883.

[20] Wylie M.J., White T.W., Ellis W.C., Matis J.H. The flow of undigested corn residues through the gastrointestinal tract of cattle, J. Anim. Sci. 68 (1990) 3843-3852. 